\title{
Comparison of Material-mediated Bone Regeneration Capacities of Sintered and Non-sintered Xenogeneic Bone Substitutes via 2D and 3D Data
}

\author{
ELENI KAPOGIANNI ${ }^{1 *}$, MIKE BARBECK $^{1,2^{*}}$, OLE JUNG $^{1,2}$, AYLIN ARSLAN $^{2}$, \\ LENNART KUHNEL $^{1}$, XIN XIONG ${ }^{3}$, RUMEN KRASTEV ${ }^{3,4}$, REINHARD E. FRIEDRICH $^{1}$, \\ REINHARD SCHNETTLER ${ }^{1}$, TIM FIENITZ ${ }^{5 *}$ and DANIEL ROTHAMEL ${ }^{5,6^{*}}$ \\ ${ }^{1}$ Department of Oral and Maxillofacial Surgery, University Hospital Hamburg-Eppendorf, Hamburg, Germany; \\ ${ }^{2}$ BerlinAnalytix GmbH, Berlin, Germany; \\ ${ }^{3}$ Natural and Medical Sciences Institute, University of Tübingen, Reutlingen, Germany; \\ ${ }^{4}$ Department of Intelligent Surfaces, Faculty of Applied Chemistry, Reutlingen University, Reutlingen, Germany; \\ ${ }^{5}$ Department of Oral and Maxillofacial Plastic Surgery, \\ Evangelic Johanniter Hospital Bethesda Mönchengladbach, Mönchengladbach, Germany; \\ ${ }^{6}$ Department of Oral and Maxillofacial Plastic Surgery, \\ Heinrich-Heine Universität Düsseldorf, Düsseldorf, Germany
}

\begin{abstract}
Background/Aim: The aim of this study was the development of a new osteoconductivity index to determine the bone healing capacities of bone substitute materials (BSM) on the basis of $3 D$ microcomputed tomographic $(\mu-C T)$ data. Materials and Methods: Sinus biopsies were used for the comparative analysis of the integration behavior of two xenogeneic BSM (cerabone ${ }^{\circledR}$ and Bio-Oss ${ }^{\circledR}$ ). $3 D \mu-C T$ and data sets from histomorphometrical measurements based on $2 D$ histological slices were used to measure the bone-materialcontact and the tissue distribution within the biopsies. The tissue reactions to both BSM were microscopically analyzed. Results: The $3 D$ and $2 D$ results of the osteoconductivity measurements showed comparable material-bone contacts for both BSM, but the 2D data were significantly lower. The same results were found when tissue distribution was measured in both groups. The histopathological analysis showed comparative tissue reactions in both BSM. Conclusion: Osteoconductivity index is a reliable measurement parameter for determining the healing capacities of BSM. The observed
\end{abstract}

This article is freely accessible online.

*These Authors contributed equally to this study.

Correspondence to: Mike Barbeck, Martinistrasse 52, 20251 Hamburg, Germany. Tel: +49 17681022467, e-mail: mike.barbeck@icloud.com

Key Words: Osteoconductivity index, micro-CT, histomorphometry, xenogeneic bone substitute, tissue response, bone regeneration. differences between both measurement methods could be assigned to the resolution capacity of $\mu$-CT data that did not allow for a precise interface distinction between both BSM and bone tissue. Histomorphometrical data based on histological slides still allow for a more exact evaluation.

Insufficient bone volume still poses a common challenge for placement of dental implants. To ensure an ideal hold of the implant in its bony implantation bed, a sufficient bone volume is vital. Different methods used for this purpose differ in the localization and various other factors $(1,2)$. In the maxillary region, sinus augmentation, also called sinus lift, is a standard technique to augment the maxillary sinus' bony floor (1). Beside autografts, allografts and alloplastic materials, xenogeneic materials have largely been established as standard bone substitute material (BSM) in the field of maxillofacial surgery and dentistry. This type of BSM is derived from bone tissue of other species (2). The structure of xenogeneic BSM is generally very similar to the structure of human bone, which explains their good regenerative properties (3-5). Prior to its application as a BSM, the bovine bone tissue must be purified due to the potentially immunogenic character of cells, extracellular matrix elements and possible pathogens (5). The most widely used xenogeneic BSM, Bio-Oss ${ }^{\circledR}$ (Geistlich Pharma AG, Wolhusen, Switzerland) and cerabone ${ }^{\circledR}$ (botiss biomaterials $\mathrm{GmbH}$, Zossen, Germany), are based on bovine bone. Interestingly, their purification processes differ in parts: In case of BioOss ${ }^{\circledR}$, heat treatment of the original tissue at $300^{\circ} \mathrm{C}$ is followed by sodium hydroxide treatment $(5,6)$. In contrast, 
the bovine bone tissue is purified by means of a two-stage heating process for cerabone ${ }^{\circledR}$ production (5). Temperatures above $800^{\circ} \mathrm{C}$ are followed by a sintering process at $1250^{\circ} \mathrm{C}$, ensuring the removal of all unwanted organic components and altering the microstructure of the material $(5,7)$.

Interestingly, it has been assumed that the different temperature treatments used for purification of the bone tissue or the bone matrix may lead to different physical properties of both BSM (5). In this context, it has been, moreover, presumed that the differences of the materials surface pattern lead to changes of the molecular basis of the tissue reaction to both BSM that induce further variations in the extent of their tissue integration and bone regeneration $(5,8)$. A preclinical in vivo study using the subcutaneous implantation model has revealed that cerabone ${ }^{\circledR}$ induces a slightly higher extent of a materialrelated foreign body response with higher numbers of biomaterial-induced multinucleated giant cells (BMGCs) up to 60 days after implantation $(5,8)$. However, only few data exist regarding the clinical consequences of these material differences $(5,8)$. It has already been shown that the application of both BSM leads to comparable values of newly built bone several months after the clinical application of both materials (9). However, these data are based on 2D data from single histological slides that were histomorphometrically analyzed on the basis of a published protocol that measures the whole fraction of bone tissue within an implantation bed of BSM without considering the material-specific osteoconductive characteristics. On this basis, the objective of this study was the development of a new "osteoconductivity index" based on histomorphometric measurement of the surface coverage of the granules of the two xenogeneic BSM by bone tissue, as indicator for the extent of material-associated tissue regeneration and its osteoconductive capacities. The new "osteoconductivity index" should be developed on the basis of microcomputed tomographic ( $\mu-\mathrm{CT})$ data to easily acquire values from the whole volume of a biopsy (3D data). For this purpose, sinus biopsies from a previous clinical study (10) were used to develop a new ImageJ (https://imagej.nih.gov/ij/) plug-in that allows for semiautomated evaluation of bone-material contact. Based on the 3D data, the comparative analysis of the integration behavior of two xenogeneic BSM was analyzed, and was also compared to "conventional" histomorphometric data (2D data). Furthermore, the tissue distribution was comparatively analyzed using both imaging processes. Finally, the tissue reactions to both bone substitute materials were analyzed following a specialized histopathological protocol (11-18).

\section{Patients and Methods}

Biomaterials. Both xenogeneic biomaterials are obtained from the femoral heads of cattle from registered slaughterhouses in Australia and New Zealand (5). Both countries carry a negligible BSE risk, according to the World Organization for Animal Health (OIE) (19). In the case of the two bone substitute materials, the potentially immunogenic constituents of the donor tissue are removed in order to guarantee a safe healing without a rejection reaction and without transmission of diseases (5). A first step in ensuring the quality of the two bone substitutes is to pre-select donor animals. Furthermore, multi-stage methods involving both chemical and physical methods are used for the purification of the original tissue of the two bone substitute materials (11). In case of the BSM Bio-Oss ${ }^{\circledR}$ the low temperature treatment was performed at a temperature of $\sim 300^{\circ} \mathrm{C}$ followed by sodium hydroxide $(\mathrm{NaOH})$ treatment (5). In contrast, the BSM cerabone ${ }^{\circledR}$ was produced by heating at temperatures of up to $1,250^{\circ} \mathrm{C}$, which is referred to as so-called sintering (5). Thus, the main difference between the purification processes of these two materials is the treatment with different high temperatures (5). After the respective purification processes both BSM are sterilized and packed.

Clinical procedure and biopsy harvest. The sinus biopsies, which were examined in the present work, were extracted from 20 patients in the course of re-entry for dental implant insertion at the Department of Oral and Maxillofacial Surgery of the University Hospital Cologne (10). The study was approved by the ethics committee of the University of Cologne and the respective local committees of Duesseldorf and Muenster, Germany. All patients were treated six months earlier with the two xenogeneic BSM for the purpose of sinus floor elevation for later dental implant insertion as follows (10): Prior to the implantation procedure, perioperative antibiosis (Amoclav $500 \mathrm{mg}$ (Hexal AG, Holzkirchen, Germany) or Clindamycin 600 mg (Clindasaar, MIP Pharma GmbH, Blieskastel, Germany) and oral disinfection by rinsing with chlorhexidine solution (Chlorhexamed Fluid, 0.1\% GlaxoSmithKline Consumer Healthcare $\mathrm{GmbH}$, Bühl, Germany) for $30 \mathrm{sec}$ were initiated. After local anaesthesia (Ultracain D-S, Sanofi-Aventis GmbH, Frankfurt, Germany), sinus augmentation was performed. Directly followed to mucoperiostal reflection, a lateral bone window was created by means of diamond burs. After that, the Schneiderian membrane was carefully elevated and a porcine pericardium-based collagen membrane (Alpha Bio's Graft ${ }^{\circledR}$, Alpha Bio, Petach Tikva, Israel) was applied underneath the Schneiderian membrane. The BSM cerabone ${ }^{\circledR}$ or Bio-Oss ${ }^{\circledR}$ were randomly applied into the cavity after rehydration in sterile saline solution and another collagen membrane was placed on the BSM. Finally, the gingival wounds were sutured (PGA Resorba, Resorba, Nuremberg, Germany). Following a healing period of six months, the biopsies were harvested after mucoperiostal reflection by means of trephine burs of 3 or 4-mm diameter (Ustomed, Tuttlingen, Germany). After further surgical preparation tooth implants (SPI ${ }^{\circledR}$, Alpha Bio, Petach Tikva, Israel) were applied and the wounds were closed by suturing.

\section{Histomorphometric analyses}

Histomorphometric measurements based on micro-computed tomography $(\mu C T)$. The sinus biopsies were scanned $(100 \mathrm{kV}, 100 \mu \mathrm{A})$ using a FF20 CT micro-computed tomograph (YXLON, Hamburg, Germany) with a detector frame rate of $3 \mathrm{~Hz}$.Focus-object distance was set to $600 \mathrm{~nm}$ and focus-detector distance to $100 \mathrm{~nm}$ for manipulation to provide an ideal image quality. Subsequently, pixels of the $\mu \mathrm{CT}$ images were converted into three-dimensional voxel units, with a voxel size of $12 \mu \mathrm{m}$. In this manner an image stack (Figures 1 and 2) was created for each specimen that reproduced all levels of a biopsy and was supplemented by the associated metadata including the recording settings. The image stacks of the individual biopsies were then used to perform histomorphometric analyses. 

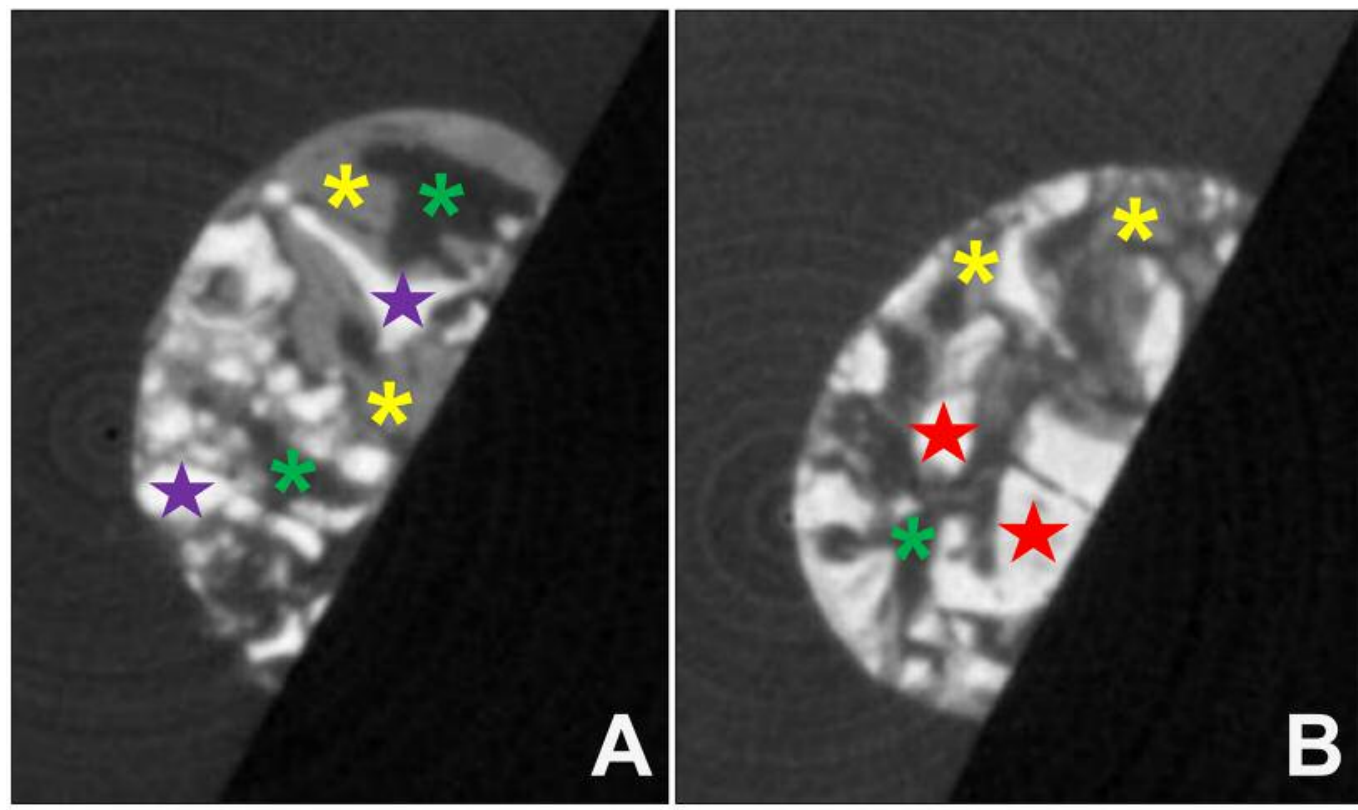

Figure 1. Exemplary images of one level from the image stacks of the $\mu$-CT data of a respective biopsy of (A) cerabone $e^{\circledR}$ or (B) Bio-Oss ${ }^{(}$. Purple stars in $A$ and red stars in $B=B S M$; yellow stars=newly formed bone tissue, green stars=connective tissue.

The histomorphometric analysis of the $\mu \mathrm{CT}$ data was performed using a newly programmed macro for the program Image J (https://imagej.nih.gov/ij/). The respective image stack of the $\mu \mathrm{CT}$ data was opened and calibrated utilizing the data from the associated metadata file in ImageJ. Subsequently, selection of the BSM, bone and connective tissue was carried out by means of the macro for all image stacks (Figure 3). This was achieved by a threshold-based measurement of density disparities of the fractions of interest. Furthermore, this separation allows for measurement of the contact length between the BSM granules and bone tissue ("osteoconductivity index", in percent (\%)) as well as the volume fraction of BSM, newly formed bone tissue and connective tissue (in $\mathrm{mm}^{3}$ ).

Histomorphometric measurements based on histology and histopathological evaluation. For the analysis of the biopsies based on $2 \mathrm{D}$ slides and for further histopathological evaluation, the specimens were histologically prepared as previously described (10). In brief, the tissue samples were dehydrated by means of a series of increasing alcohol concentrations and a xylol exposure. After that embedding in polymethylmethacrylate (PMMA, Heraeus Kulzer, Wehrheim, Germany) was performed, followed by the preparation of sections with a thickness of 10-15 $\mu \mathrm{m}$, using a rotation microtome (SLEE, Mainz, Germany). Then, the sections were treated with hydrogen peroxide, decalcified by formic acid and histochemically stained using specialized dyes for bone samples, i.e., hematoxylin and eosin (H\&E), toluidine blue and Movat pentachrome and Alcian blue, as previously described $(8,12,20,21)$.

For histomorphometric analysis, an Axio Imager 2 microscope (Carl Zeiss AG, Oberkochen, Germany) and the software package Zen 2 core (Carl Zeiss Microscopy GmbH, Jena, Germany) were used for the digitization of the histological slides and the subsequent histomorphometric measurements (Figure 4). For determining the osteoconductivity, the surface length of the single BSM granules and also the length of the BSM-bone-contact were measured. Afterwards, the osteoconductivity was calculated by forming the quotient of the total contact area and the total granule surface length. For calculation of the tissue distribution the area of the entire implant area of the BSM was initially measured. Then, the areas of the different fractions, i.e., the newly formed bone, the remaining BSM and the connective tissue, were measured. Furthermore, the percentage values of these fractions were calculated by forming the quotient of the respective fraction areas and the total implantation area.

Statistical analysis. The histomorphometric data were subjected to an analysis of variance (ANOVA). For more detailed statistical analysis, an LSD (least significant difference) post-hoc test was then performed using the software GraphPad Prism (version 7.0e, GraphPad Software Inc., La Jolla, CA, USA). Statistical differences were found to be significant with $p$-values of $p<0.05(* p<0.05)$, $p<0.01 \quad(* * p<0.01)$ or $p<0.001 \quad(* * * p<0.001)$. In addition, a Welch's t-test was carried out for the evaluation of the contact surfaces with bone tissue.

\section{Results}

Osteoconductivity measurements. Measurement of the BMSbone contact area, i.e., the measurement of the materialrelated osteoconductivity index, based on $\mu$-CT data showed that BSM cerabone ${ }^{\circledR}$ and Bio-Oss ${ }^{\circledR}$ had comparable values; an average of $92.72 \pm 8.77 \%$ in the cerabone ${ }^{\circledR}$ group and of $88.84 \pm 8.81 \%$ in the Bio-Oss ${ }^{\circledR}$ group (Figure 5). 

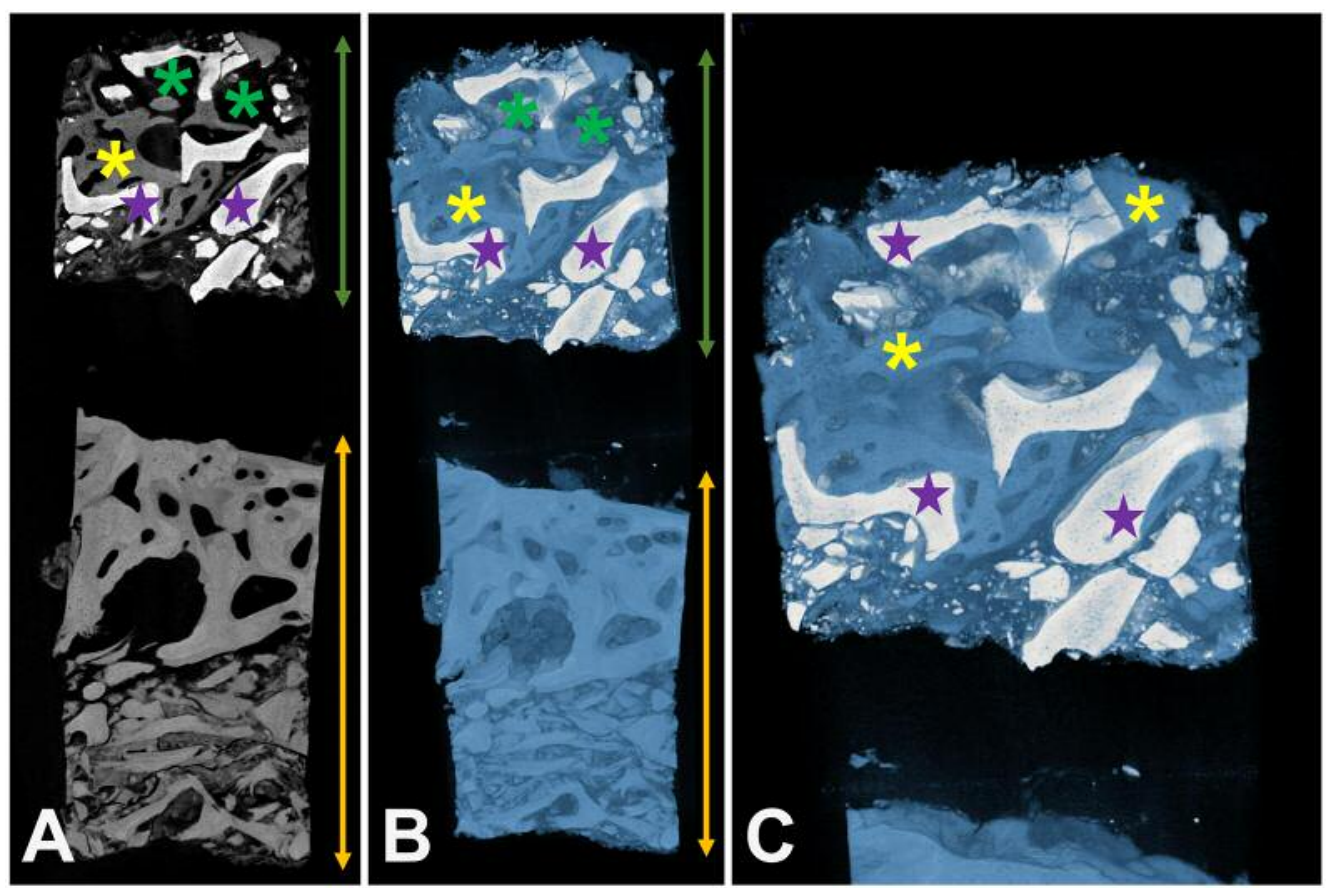

Figure 2. Exemplary reconstruction of a biopsy including the BSM cerabone ${ }^{\circledR}$. (A) $2 D$ overview of the biopsy. (B) and (C) $3 D$ reconstruction of the biopsy. Green double arrows: implantation area; yellow double arrows: residual bone; purple stars: xenogeneic BSM; yellow stars: newly formed bone, green stars: connective tissue.

Measurement of the osteoconductivity index based on the data obtained from histological slides showed also comparable values in both study groups (Figure 5). Mean contact areas were $22.66 \pm 17.87 \%$ in the cerabone ${ }^{\circledR}$ group and of $16.59 \pm 5.44 \%$ in the Bio-Oss ${ }^{\circledR}$ group (Figure 5).

The comparison of the two different imaging methods showed that the values derived from histological slides were significantly lower $(p<0.001)$ compared to the data obtained through $\mu$-CT (Figure 5).

Tissue distribution measurements. Measurements derived from $\mu$-CT data showed that the average tissue distribution was $50.12 \pm 10.97 \%$ bone tissue, $16.12 \pm 10.11 \%$ remaining BSM and $33.77 \pm 10,81 \%$ connective tissue in the group of the BSM cerabone ${ }^{\circledR}$ (Figure 6). Comparable average distributions were found in the $\mathrm{Bio-Oss}{ }^{\circledR}$ group; $44.02 \pm 10.48 \%$ bone tissue, $18.06 \pm 12.53 \%$ remaining BSM and of $37.92 \pm 8.28 \%$ connective tissue (Figure 6). No significant differences between the different values in the two groups were found.

Furthermore, the histomorphometrical measurements based on histological slides showed that the average tissue distribution was $20.4 \pm 8.22 \%$ bone tissue, $29.82 \pm 11.75 \%$ residual BSM and $49.78 \pm 10.37 \%$ connective tissue in the cerabone ${ }^{\circledR}$ group (Figure 6). In the BSM Bio-Oss ${ }^{\circledR}$ group, the average tissue distribution $23.95 \pm 8.89 \%$ bone tissue, $23.47 \pm 8.26 \%$ remaining BSM and
$52.57 \pm 3,89 \%$ connective tissue (Figure 6 ). Also, no significant differences were identified between the values in the two study groups (Figure 6).

However, significantly lower amounts of newly formed bone tissue $(p<0.001)$ were found through the analysis of the histological slides compared to $\mu$-CT data in both study groups (Figure 6). Furthermore, a significantly lower amount of remaining BSM $(p<0.001)$ was found in the case of the BSM cerabone ${ }^{\circledR}$ using $\mu$-CT data compared to the data obtained using conventional histomorphometry, while no differences were calculated between the $\mu$-CT and histomorphometry data in the Bio-Oss ${ }^{\circledR}$ group (Figure 6). Moreover, the amount of connective tissue measured via histomorphometry were significantly higher $(p<0.001)$ than the values measured via $\mu$-CT in both groups (Figure 6).

Histopathological investigations of tissue reactions. The histopathological examinations of the tissue responses to the two xenogeneic BSM revealed that the granules of both BSM were predominantly surrounded by newly formed bone tissue (Figure 7A and B). Often only thin layers of newly built bone matrix with already embedded osteocytes as well as active osteoblasts could be detected on the granule surfaces in both study groups, which indicated the active process of bone growth (Figure 7A-D). Altogether, no visible differences in bony integration between the two BSM could be observed. 


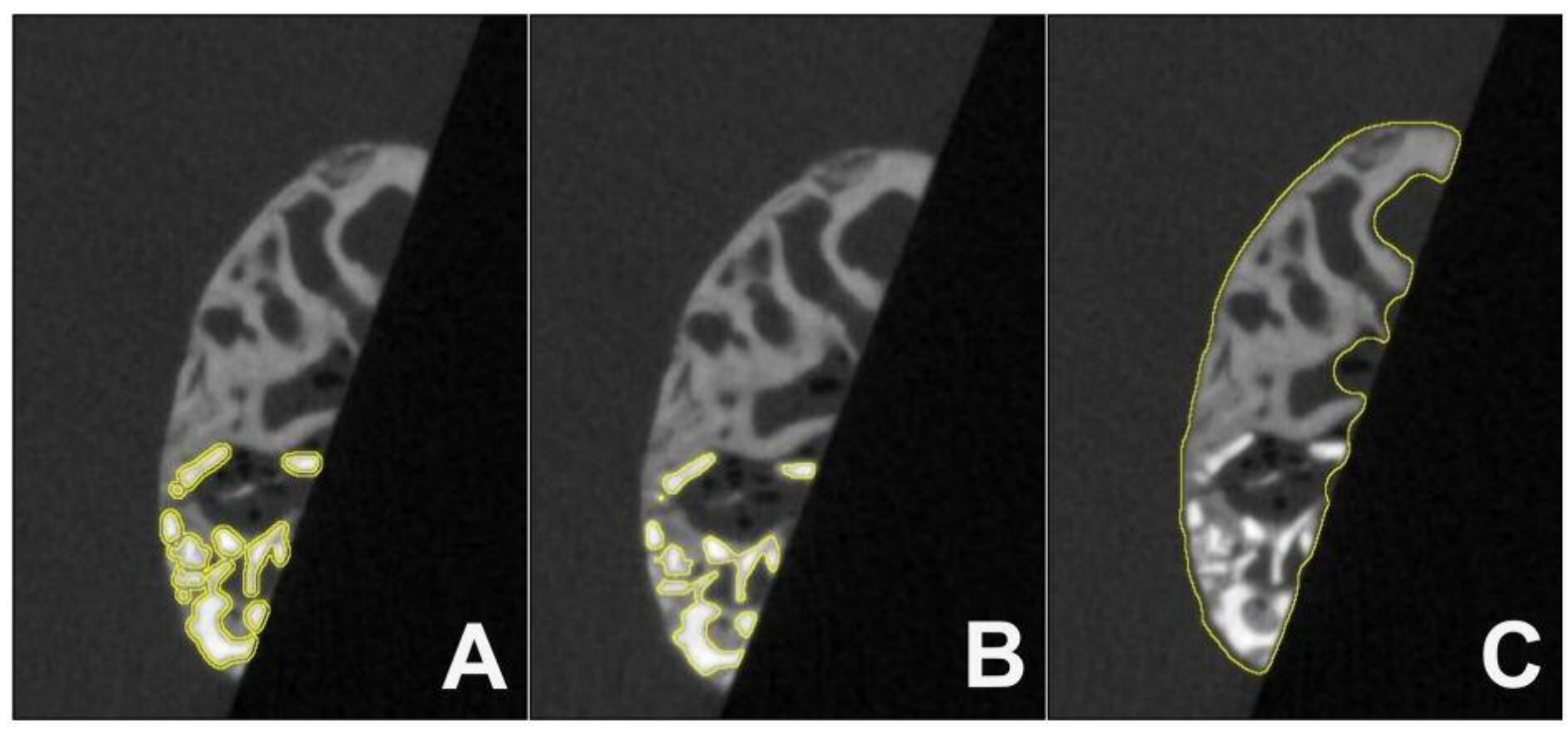

Figure 3. Exemplary images of one level of a $\mu$-CT image stack showing the implantation site of cerabone ${ }^{\circledR}$ with different regions of interest (ROI). (A) ROI of the contact surface between the BSM granules and the newly formed bone tissue. (B) ROI of the BSM granules. (C) ROI of the total implantation area (each marked by a yellow line).

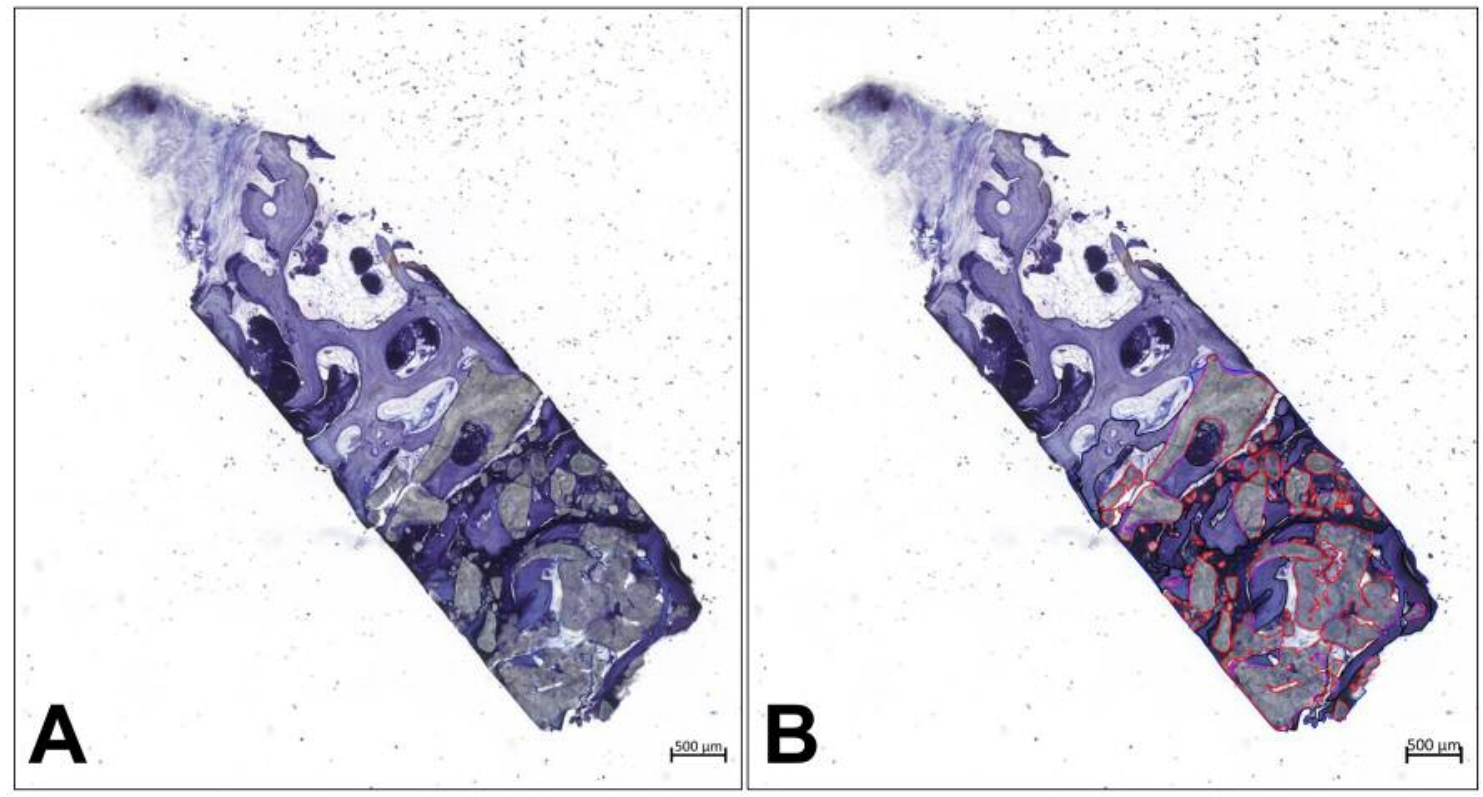

Figure 4. Histopathology and histomorphometric measurements. (A) Exemplary total scan of a sinus biopsy before histomorphometry. (B) Histomorphometrical measurement of the area of the remaining BSM (red lines) (both images: toluidine blue staining, "total scans", $\times 100$ magnification, scale bars $=500 \mu \mathrm{m})$.

Moreover, the histopathological investigation of materialinduced inflammatory tissue responses showed that almost exclusively mononuclear cells of the macrophage lineage were found on the granule surfaces that were adjacent to connective tissue in the group of the BSM cerabone ${ }^{\circledR}$ (Figure $7 \mathrm{E})$. Within the adjacent connective tissue slightly increased amounts of inflammatory cells, i.e., mainly macrophages beside lower amounts of granulocytes and a variety of 


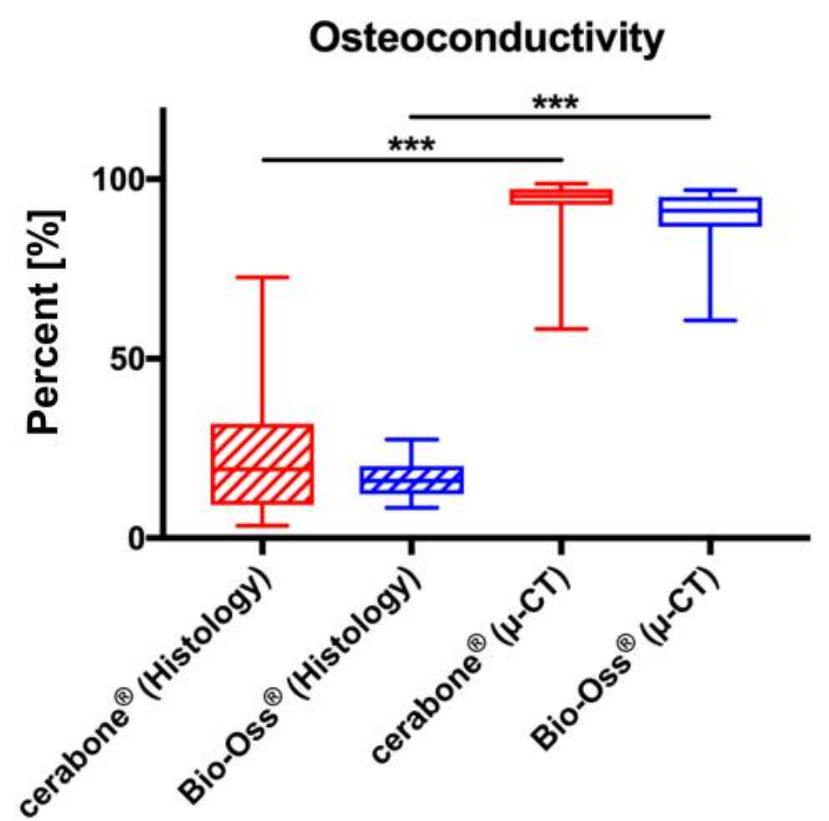

Figure 5. Results of the histomorphometrical analyses of the BSM-bone contact areas as basis of the newly developed osteoconductivity index in the groups of the BSM cerabone ${ }^{\circledR}$ and Bio-Oss ${ }^{\circledR}$ assessed through $\mu$-CT and histological slide analysis.

fibroblasts, were observed in this study group (Figure 7E). In the group of the BSM Bio-Oss ${ }^{\circledR}$, several biomaterialassociated multinucleated giant cells were found at the material surfaces in addition to mononuclear cells, which were mainly assigned to the macrophage line (Figure 7D and F). In some areas the presence of circular collagen fibers surrounding the BSM granules suggested a slight fibrotic reaction (Figure 7D and $\mathrm{F}$ ). Within the adjacent connective tissue an inflammatory tissue reaction with numerous macrophages and granulocytes next to significantly lower amounts of fibroblasts was observed (Figure 7D and F).

\section{Discussion}

The tissue of origin of natural BSM must be purified prior to application in order to guarantee a safe clinical application. In some cases, purification processes and thus purification results show considerable variation (5). The two most widely used BSM Bio-Oss ${ }^{\circledR}$ and cerabone ${ }^{\circledR}$ are of bovine origin and their purification processes mainly differ with regard to temperature treatment (5). Bio-Oss ${ }^{\circledR}$ is treated with a strong alkaline sodium hydroxide solution after a temperature treatment of $300^{\circ} \mathrm{C}$ and is thus not sintered (5). In contrast, cerabone ${ }^{\circledR}$ is sintered at high temperatures of around $1200^{\circ} \mathrm{C}(5)$. These different temperature treatments are presumed to influence the physical and chemical

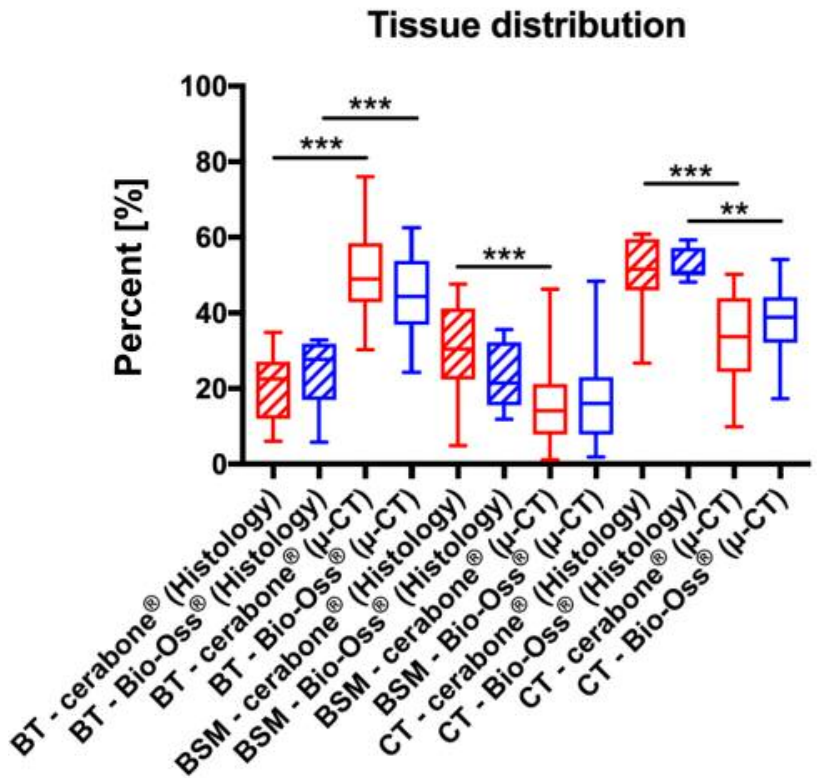

Figure 6. Results of the histomorphometrical analyses of the tissue distribution in the groups of the BSM cerabone ${ }^{\circledR}$ and Bio-Oss ${ }^{\circledR}$ assessed through $\mu$-CT and histological slide analysis.

properties of BSM, which should, therefore, lead to variations of the material-associated inflammatory tissue reactions as well as the healing process and osteoconductive bone growth (5).

In this context, it has been revealed that the inflammatory tissue response to a biomaterial is initiated by the attachment of proteins. The composition of this initial protein layer is dependent on the physical properties of the material such as surface texture as well as its chemical nature, i.e., the sum of the physicochemical characteristics of the biomaterial (22). Overall, the protein layer on the surface of a biomaterial is thus a material-specific component of the inflammation cascade that develops after its implantation (22). Dependent on the attached proteins and their respective conformation, cell binding sites are exposed which in each case cause specific cellular inflammatory reactions through signal transduction (22). In the subsequent phase, notably macrophages are induced to express a specific range of cytokines, which depends on the binding to the materialspecific protein binding sites $(22,23)$. Based on the varying expression of pro- and anti-inflammatory cytokines important parameters such as implant bed vascularization and material-associated bone healing processes are influenced $(5,22)$. Moreover, different amounts of biomaterial-associated multinucleated giant cells (BMGCs) are induced, which have been shown to be involved in tissue 

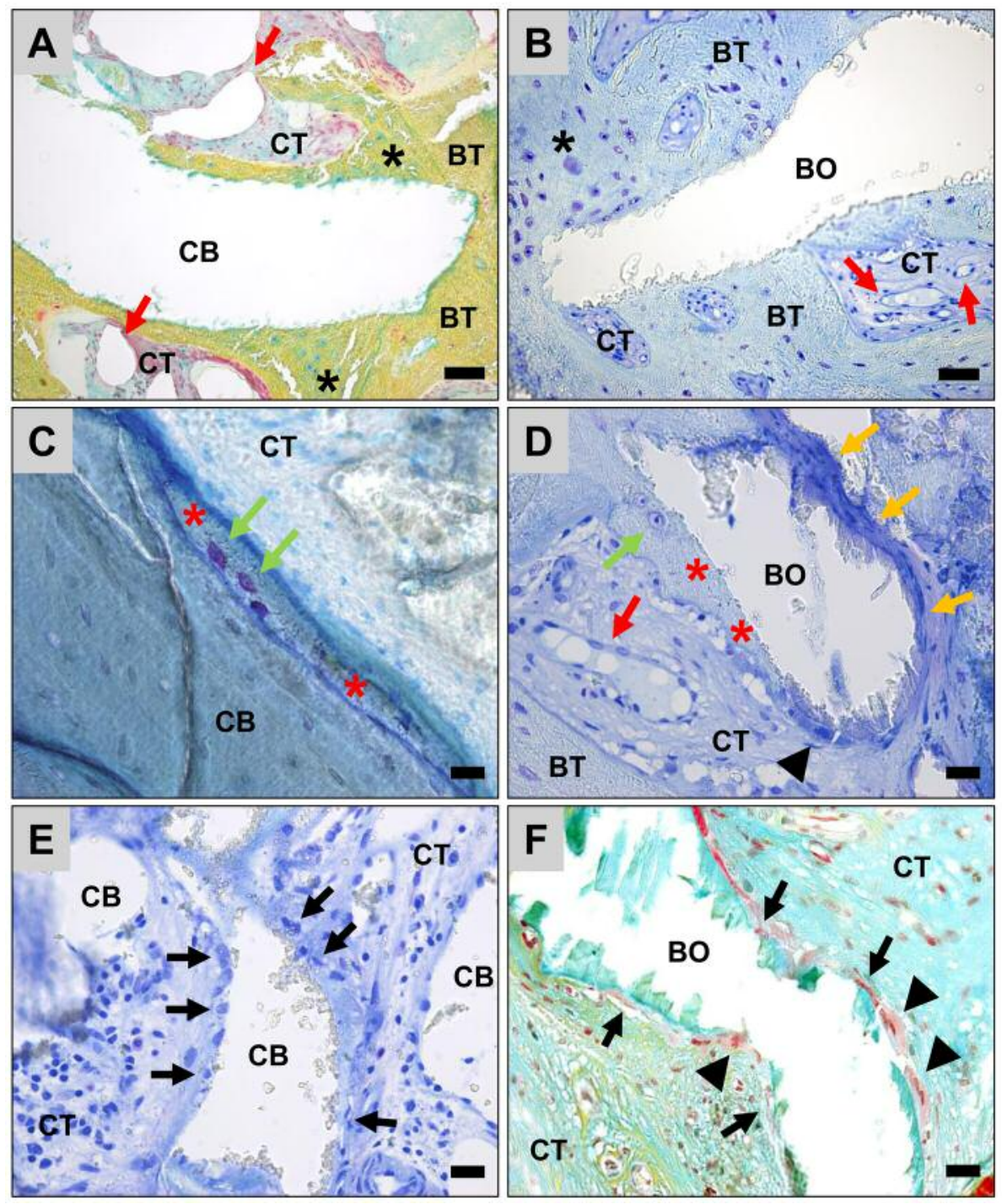

Figure 7. Tissue integration and cellular responses to the two BSM. A, C, E: Cerabone ${ }^{\circledR}(C B)$ and B, D, F: Bio-Oss ${ }^{\circledR}(B O)$. BT: Bone tissue; CT: connective tissue; black stars: areas of active bone formation with signs of active osteoblasts; red arrows: blood vessels; green arrows: walled osteocytes surrounded by pre-calcified bone matrix; red stars: bone matrix margins on the granule surfaces; black arrows: mononuclear cells on the material surface; black arrowheads: material-associated multinucleated giant cells. (A: Movat's pentachrome staining, B: toluidine staining, A and B: $\times 200$-magnification, scale bar $=50 \mu \mathrm{m}, C$-E: toluidine staining, $F:$ Movat's pentachrome staining, $\times 400$-magnification, scale bars=20 $\mu \mathrm{m})$.

reaction comparable to their mononuclear precursors by expression of molecules such as the heme oxygenase-1 (HO-1), the mannose receptor (MR, also known as CD206) and the vascular endothelial growth factor, besides, proinflammatory signaling molecules $(17,24)$.

Based on the temperature treatments of the two abovedescribed xenogeneic BSM and previously published preclinical data it has been suggested that their clinical application might lead to different healing outcomes $(5,8)$. These preclinical studies revealed substantial differences in the material-induced inflammatory tissue responses due to the differential surface textures of Bio-Oss ${ }^{\circledR}$ and cerabone ${ }^{\circledR}$ $(3,5,6,8)$. In the primary phase after implantation cerabone ${ }^{\circledR}$ showed a higher bioactivity together with higher numbers of multinucleated giant cells compared to BioOss ${ }^{\circledR}$, combined with a higher implant bed vascularization. However, previous clinical studies have already shown that comparable levels of new bone formation were found for both BSM (9). Interestingly, comparable levels of bone healing were also measured in the present study, which shows that the described material differences may not have major influence onto the final clinical success of a BSM. 
However, the healing capacities of BSM have often been determined through the histomorphometrical analysis using 2D histological slides from an implantation bed. As also presumed in different other studies, the measurement of the whole bone fraction in a histological slide might not reflect the extent of osteoconductivity by a BSM (25). Thus, it has been hypothesized that the analysis of the BSM-bone-contact based on 3D data such as $\mu$-CT data provides a more reliable measurement for the regenerative potential of a bone substitute based on its osteoconductive properties. Therefore, the main focus of this study was to develop a novel "osteoconductivity index" based on $\mu$-CT data, which will reflect the materialassociated bone healing process within the entire implantation area of a BSM. For this measurement a new macro for the scientific freeware ImageJ was programmed. To substantiate the reliability of the new osteoconductivity index, also "conventional" histomorphometry of histological slides using previously described methods was conducted $(8,12,20,26)$.

Interestingly, the results of these measurements, based on the two different imaging techniques, showed that the $\mu$-CTbased values were significantly higher $(92.72 \pm 8.77 \%$ for cerabone $^{\circledR}$ and $88.84 \pm 8.81 \%$ for Bio-Oss ${ }^{\circledR}$ ) compared with the data obtained via the histology-based 2D measurements $\left(22.66 \pm 17.87 \%\right.$ for cerabone ${ }^{\circledR}$ and $16.59 \pm 5.44 \%$ for BioOss ${ }^{\circledR}$ ) although no differences were found comparing the material-related data of both groups. Thus, the contact surfaces measured by the two imaging methods differed substantially and did not correlate with each other. Based on the significant differences, it could be concluded that the values obtained by one of the imaging techniques are inaccurate. On one hand, these discrepancies in the values of the imaging techniques can be explained by the fact that only one layer of a biopsy was examined in the case of histomorphometry, while $\mu$-CT provides thorough in-depth analyses. This means that individual biopsy parts such as the parts of the biopsies that are within the defect may differ immensely from the parts that are in the periphery of the defect. As a result, the extent of bony healing measured on basis of the histological slides could be contorted and, thus, may not reflect the state of bone growth within the whole implantation bed. However, in combination with the histopathological data, which revealed that in most biopsies the material granules in both groups were not completely covered by newly formed bone tissue, it can be concluded that the values that are based on the $\mu$-CT-based measurements are inaccurate. Moreover, it has already been shown that the osseointegration of most BSM is nearly complete after 6 months up to the center and the upper border of an implantation bed after sinus augmentation (12, 20). Based on these findings, it can be assumed that the values measured on the basis of the histologies are more appropriate than those obtained via $\mu$-CT data. A further reason for this difference can be the differential resolution or selectivity of the two methods. This means that the higher surface contact of the BSM determined by $\mu$-CT analysis derived from lower selectivity of the different fractions based on similar gray values of the natural BSM and the newly formed bone. In this case, the $\mu$-CT-based solution interprets the borders of the granules as newly formed bone tissue, which leads to distortion of the data. In this context, it should be mentioned that both BSM were obtained from bovine bone tissue, whose purified bone matrix and its similarity to the human bone matrix might be the reason for the similarity of their gray scales. Therefore, conventional histology-based analysis regarding the development of an osteoconductivity index should be preferred to $\mu$-CT-based methodology. Although different studies have confirmed the compliance of histology-based and $\mu$-CT-based bone tissue measurements and also the analyses of bone-implant contact (27-29), the present study involving both xenogeneic BSM did not allow for a $\mu$-CT-based examination of the target structure. To overcome this issue the use of improved analyzers with significantly higher resolutions in the nanometer range, socalled nano-CT devices with resolutions of $50 \mathrm{~nm}$ (30), may allow acquisition of better results with higher selectivity between the different parts within a biopsy compared to conventional $\mu$-CT devices with resolutions of about $6 \mu \mathrm{m}$ (31). Based on the present methods and results, subsequent studies are already planned to allow for further comparison and validation of the present data.

Another result of the present study was the comparative measurement of the percentages of the tissue fractions within the biopsies. Interestingly, also for the tissue distribution measurements, a clear difference was observed between the data obtained by $\mu-\mathrm{CT}$ and histology. These differences may be due to inhomogeneous healing of the defect area with newly formed bone and connective tissue, since the amounts of the contained BSM are the most comparable fractions. The lack of selectivity regarding tissue distribution measurements may be neglected since the majority of BSM was easily detected and analyzed and not only the interface area. Interestingly, these results were comparable to a study conducted by Müller et al. (27) that also has revealed a correlation between the two methods. In contrast, Chackartchi et al. have not identified any correlation between 2D and 3D methods (25). Thus, additional studies should optimize or further validate the measurement accuracy of the two methods.

A comparison with the literature regarding the values of tissue distribution showed that the tissue distribution values in case of cerabone ${ }^{\circledR}$ were comparable to those from another clinical study, which were calculated on the basis of histological slides (12). In one of these studies, Tawil et al. have also applied cerabone ${ }^{\circledR}$ for 5-6 months for the purpose of sinus augmentation and they have shown values of $22.77 \pm 5.89 \%$ of newly formed bone, $34.9 \pm 7.10 \%$ of remaining 
BSM and $42.29 \pm 8.98 \%$ of connective tissue (12). Moreover, different studies have shown comparable tissue fractions values after clinical application of the BSM Bio-Oss ${ }^{\circledR}(5,32,33)$. For example, in the study by Yong-Moo Lee et al. tissue distributions were $18.3 \pm 5.4 \%$ newly formed bone tissue, $29.8 \pm 8.8 \%$ remaining $\mathrm{BSM}$, and $52.0 \pm 6,6 \%$ connective tissue for Bio-Oss ${ }^{\circledR}$ (34). Thus, these results also correspond to the data obtained by conventional histomorphometry measurements in the present work and can hence confirm the comparability and validity of this histomorphometric measurement method. Especially, it should be emphasized that no differences in osteoconductivity or tissue distribution were found for the two BSM by the histology-based or the $\mu$-CTbased data. These results are of particular importance as they show that the application of both xenogeneic BSM leads to comparable extents of osteoconductive bone growth. These results are furthermore substantiated by other studies such as an examination by Panagiotou et al. that have also revealed comparable results with no significant differences in osseous regeneration between Bio-Oss ${ }^{\circledR}$ and cerabone ${ }^{\circledR}$ after 8 months (9). These data lead to the conclusion that the previously described different material characteristics have no influence on bony healing.

In addition, the tissue reactions to the two xenogeneic BSM were analyzed by histopathological evaluation following a previously published protocol (12). The analysis showed that Bio-Oss ${ }^{\circledR}$ and cerabone ${ }^{\circledR}$ were integrated into newly formed bone tissue to a large part without visible differences between $\tau \eta \varepsilon \mu$. Furthermore, the investigation of material-induced inflammatory tissue responses showed that cerabone ${ }^{\circledR}$ induced a slight inflammatory tissue reaction mostly involving cells of the macrophage lineage and only very low numbers of biomaterial-associated multinucleated giant cells (BMGCs). In contrast, in the group of BSM BioOss ${ }^{\circledR}$, higher numbers of BMGCs were found at the material surfaces in addition to macrophages combined with the presence of circular collagen fibers, which seems to be a slight fibrotic reaction. No differences in the implantation bed vascularization were observed between the study groups. These results are in line with various other studies that have analyzed the osteoconductive integration behavior and the biocompatibility of both BSM $(8,34-38))$. Interestingly, also previous preclinical and clinical studies have revealed differences of the (initial) tissue reactions to the two BSM, mainly due to different numbers of BMGCs and different implant bed vascularization (5). Interestingly, it was observed that cerabone ${ }^{\circledR}$ induced higher numbers of BMGCs and a higher implant bed vascularization, which was assumed to be due to the afore-mentioned different characteristics of the two biomaterials (5). However, higher numbers of BMGCs were found in case of Bio-Oss ${ }^{\circledR}$ in the present study obviously without influence onto the overall bone regeneration process. These results lead to the conclusion that the initially observed tissue reactions may have subsided and fallen to a comparable level after a period of up to 6 months. Consequently, it can be deduced that initially different tissue reactions have no influence on longterm reaction to BSM. The results of the present study further showed that the material-related inflammatory tissue response was still detectable for both BSM, but can be classified as very low, similar to the findings of Barbeck et al. who have observed a decrease of inflammation to a low level after an initially strong tissue response to Bio-Oss ${ }^{\circledR}(8)$.

In summary, it can be concluded that there is no difference in bony healing mediated by the two investigated xenogeneic BSM - the osteoconductivity covered material surfaces and the bone volume - after several months of healing. Furthermore, similar tissue reactions indicate that differences in the methods of preparing the donor tissue have no longterm influences on tissue reactions and material-assisted bony healing. Thus, both materials serve as biocompatible and osteoconductive scaffolds without undergoing significant degradation.

\section{Conflicts of Interest}

The Authors declare no conflicts of interest regarding this study.

\section{Authors' Contributions}

TF and DR conducted the clinical study. EK, MB, OJ and AA conducted the histomorphometrical analyses. EK, MB, OJ, AA, LK, TF and DR wrote the manuscript. MB, RS, MG, RF and RS provided lab space and materials. All Authors have reviewed the manuscript and approved its publication.

\section{Acknowledgements}

The Authors would like to thank Anne-Kathrin Kopp, Berlin, for her great technical work, and Torsten Müller, Berlin, for his excellent organization support. We continue to thank Martin Gosau and Ralf Smeets for their organizational support.

\section{References}

1 Terheyden H, Jepsen S, Möller B and Rueger DJL-r-o: Sinusbodenaugmentation mit simultaner implantatinsertion unter verwendung von rekombinantem humanem osteogenic protein1. Laryngo-Rhino-Otol 80(01): 47-51, 2001. DOI: $10.1055 / \mathrm{s}-$ 2001-11032

2 Browaeys H, Bouvry P and De Bruyn H: A literature review on biomaterials in sinus augmentation procedures. Clin Implant Dent Relat Res 9(3): 166-177, 2007. PMID: 17716261. DOI: 10.1111/j.1708-8208.2007.00050.x

3 Ramírez Fernández MP, Mazón P, Gehrke SA, Calvo-Guirado JL and De Aza PN: Comparison of two xenograft materials used in sinus lift procedures: Material characterization and in vivo behavior. Materials 10(6): 623, 2017. PMID: 28772984. DOI: 10.3390/ma10060623 
4 Lüllmann-Rauch R: Taschenlehrbuch histologie. Georg Thieme Verlag, 2006.

5 Peric Kacarevic Z, Kavehei F, Houshmand A, Franke J, Smeets R, Rimashevskiy D, Wenisch S, Schnettler R, Jung O and Barbeck M: Purification processes of xenogeneic bone substitutes and their impact on tissue reactions and regeneration. Int J Artif Organs 41(11): 789-800, 2018. PMID: 29707988. DOI: $10.1177 / 0391398818771530$

6 Barbeck M, Unger R, Witte F, Wenisch S and Schnettler R: Xenogeneic bone grafting materials. Int Mag Oral Implant 3: 3436, 2017.

7 Seidel P and Dingeldein E: Cerabone ${ }^{\circledR}$-eine spongiosa-keramik bovinen ursprungs. Materialwiss Werkstofftech 35(4): 208-212, 2004. DOI: $10.1002 /$ mawe.200400734

8 Barbeck M, Udeabor S, Lorenz J, Schlee M, Holthaus MG, Raetscho N, Choukroun J, Sader R, Kirkpatrick CJ and Ghanaati $\mathrm{S}$ : High-temperature sintering of xenogeneic bone substitutes leads to increased multinucleated giant cell formation: In vivo and preliminary clinical results. J Oral Implantol 41(5): e212222, 2015. PMID: 25105868. DOI: 10.1563/aaid-joi-D-14-00168

9 Panagiotou D, Ozkan Karaca E, Dirikan Ipci S, Cakar G, Olgac $\mathrm{V}$ and Yilmaz S: Comparison of two different xenografts in bilateral sinus augmentation: Radiographic and histologic findings. Quintessence Int 46(7): 611-619, 2015. PMID: 25699296. DOI: 10.3290/j.qi.a33686

10 Fienitz T, Moses O, Klemm C, Happe A, Ferrari D, Kreppel M, Ormianer Z, Gal M and Rothamel D: Histological and radiological evaluation of sintered and non-sintered deproteinized bovine bone substitute materials in sinus augmentation procedures. A prospective, randomized-controlled, clinical multicenter study. Clin Oral Investig 21(3): 787-794, 2017. PMID: 27129584. DOI: 10.1007/s00784-016-1829-9

11 Korzinskas T, Jung O, Smeets R, Stojanovic S, Najman S, Glenske K, Hahn M, Wenisch S, Schnettler R and Barbeck M: In vivo analysis of the biocompatibility and macrophage response of a non-resorbable ptfe membrane for guided bone regeneration. Int J Mol Sci 19(10): 2952, 2018. PMID: 30262765. DOI: $10.3390 / \mathrm{ijms} 19102952$

12 Tawil G, Barbeck M, Unger R, Tawil P and Witte F: Sinus floor elevation using the lateral approach and window repositioning and a xenogeneic bone substitute as a grafting material: A histologic, histomorphometric, and radiographic analysis. Int J Oral Maxillofac Implants 33(5): 1089-1096, 2018. PMID: 29894551. DOI: $10.11607 /$ jomi.6226

13 Barbeck M, Serra T, Booms P, Stojanovic S, Najman S, Engel E, Sader R, Kirkpatrick CJ, Navarro M and Ghanaati S: Analysis of the in vitro degradation and the in vivo tissue response to bi-layered 3d-printed scaffolds combining pla and biphasic pla/bioglass components - guidance of the inflammatory response as basis for osteochondral regeneration. Bioact Mater 2(4): 208-223, 2017. PMID: 29744431. DOI: 10.1016/j.bioactmat.2017.06.001

14 Barbeck M, Booms P, Unger R, Hoffmann V, Sader R, Kirkpatrick CJ and Ghanaati S: Multinucleated giant cells in the implant bed of bone substitutes are foreign body giant cells-new insights into the material-mediated healing process. J Biomed Mater Res A 105(4): 1105-1111, 2017. PMID: 28093892. DOI: 10.1002/jbm.a.36006

15 Barbeck M, Unger RE, Booms P, Dohle E, Sader RA, Kirkpatrick CJ and Ghanaati S: Monocyte preseeding leads to an increased implant bed vascularization of biphasic calcium phosphate bone substitutes via vessel maturation. J Biomed Mater Res A 104(12): 2928-2935, 2016. PMID: 27419378. DOI: 10.1002/jbm.a.35834

16 Smeets R, Barbeck M, Hanken H, Fischer H, Lindner M, Heiland M, Woltje M, Ghanaati S and Kolk A: Selective lasermelted fully biodegradable scaffold composed of poly(d,1lactide) and beta-tricalcium phosphate with potential as a biodegradable implant for complex maxillofacial reconstruction: In vitro and in vivo results. J Biomed Mater Res B Appl Biomater 105(5): 1216-1231, 2017. PMID: 27062073. DOI: 10.1002/jbm.b.33660

17 Barbeck M, Motta A, Migliaresi C, Sader R, Kirkpatrick CJ and Ghanaati S: Heterogeneity of biomaterial-induced multinucleated giant cells: Possible importance for the regeneration process? J Biomed Mater Res A 104(2): 413-418, 2016. PMID: 26422451. DOI: 10.1002/jbm.a.35579

18 Barbeck M, Najman S, Stojanovic S, Mitic Z, Zivkovic JM, Choukroun J, Kovacevic P, Sader R, Kirkpatrick CJ and Ghanaati S: Addition of blood to a phycogenic bone substitute leads to increased in vivo vascularization. Biomed Mater 10(5): 055007 , 2015. PMID: 26359820 DOI: 10.1088/1748-6041/10/5/055007

19 Wenz B, Oesch B and Horst M: Analysis of the risk of transmitting bovine spongiform encephalopathy through bone grafts derived from bovine bone. Biomaterials 22(12): 15991606, 2001. PMID: 11374460. DOI: 10.1016/s0142-9612(00) 00312-4

20 Ghanaati S, Barbeck M, Lorenz J, Stuebinger S, Seitz O, Landes C, Kovacs AF, Kirkpatrick CJ and Sader RA: Synthetic bone substitute material comparable with xenogeneic material for bone tissue regeneration in oral cancer patients: First and preliminary histological, histomorphometrical and clinical results. Ann Maxillofac Surg 3(2): 126-138, 2013. PMID: 24205471. DOI: 10.4103/2231-0746.119221

21 Ghanaati S, Barbeck M, Willershausen I, Thimm B, Stuebinger S, Korzinskas T, Obreja K, Landes C, Kirkpatrick CJ and Sader RA: Nanocrystalline hydroxyapatite bone substitute leads to sufficient bone tissue formation already after 3 months: Histological and histomorphometrical analysis 3 and 6 months following human sinus cavity augmentation. Clin Implant Dent Relat Res 15(6): 883-892, 2013. PMID: 22251462. DOI: 10.1111/j.1708-8208.2011.00433.x

22 Anderson JM, Rodriguez A and Chang DT: Foreign body reaction to biomaterials. Semin Immunol 20(2): 86-100, 2008. PMID: 18162407. DOI: 10.1016/j.smim.2007.11.004

23 McNally AK, Jones JA, MacEwan SR, Colton E and Anderson JM: Vitronectin is a critical protein adhesion substrate for il4-induced foreign body giant cell formation. J Biomed Mater Res 86(2): 535-543, 2008. PMID: 17994558. DOI: 10.1002/jbm.a.31658

24 Ghanaati S, Barbeck M, Orth C, Willershausen I, Thimm BW, Hoffmann C, Rasic A, Sader RA, Unger RE, Peters F and Kirkpatrick CJ: Influence of beta-tricalcium phosphate granule size and morphology on tissue reaction in vivo. Acta Biomater 6(12): 4476-4487, 2010. PMID: 20624495. DOI: 10.1016/ j.actbio.2010.07.006

25 Chackartchi T, Iezzi G, Goldstein M, Klinger A, Soskolne A, Piattelli A and Shapira L: Sinus floor augmentation using large (1-2 $\mathrm{mm})$ or small $(0.25-1 \mathrm{~mm})$ bovine bone mineral particles: A prospective, intra-individual controlled clinical, microcomputerized tomography and histomorphometric study. Clin 
Oral Implants Res 22(5): 473-480, 2011. PMID: 21087317. DOI: 10.1111/j.1600-0501.2010.02032.x

26 Lorenz J, Barbeck M, Kirkpatrick CJ, Sader R, Lerner H and Ghanaati S: Injectable bone substitute material on the basis of beta-tcp and hyaluronan achieves complete bone regeneration while undergoing nearly complete degradation. Int $\mathrm{J}$ Oral Maxillofac Implants 33(3): 636-644, 2018. PMID: 29543928. DOI: $10.11607 /$ jomi.6026

27 Muller R, Van Campenhout H, Van Damme B, Van Der Perre G, Dequeker J, Hildebrand $\mathrm{T}$ and Ruegsegger P: Morphometric analysis of human bone biopsies: A quantitative structural comparison of histological sections and micro-computed tomography. Bone 23(1): 59-66, 1998. PMID: 9662131. DOI: 10.1016/s8756-3282(98)00068-4

28 Kochi G, Sato S, Ebihara H, Hirano J, Arai Y and Ito K: A comparative study of microfocus ct and histomorphometry in the evaluation of bone augmentation in rat calvarium. J Oral Sci 52(2): 203-211, 2010. PMID: 20587943.

29 Rebaudi A, Koller B, Laib A and Trisi P: Microcomputed tomographic analysis of the peri-implant bone. Int J Periodontics Restorative Dent 24(4): 316-325, 2004. PMID: 15446401.

30 Epting WK, Gelb J and Litster S: Resolving the three-dimensional microstructure of polymer electrolyte fuel cell electrodes using nanometer-scale x-ray computed tomography. Adv Funct Mater 22(3): 555-560, 2012. DOI: 10.1002/adfm.201101525

31 Schell J, Renggli M, Van Lenthe G, Müller R and Ermanni P: Micro-computed tomography determination of glass fibre reinforced polymer meso-structure. Compos Sci Technol 66(13): 2016-2022, 2006. DOI: 10.1016/j.compscitech.2006.01.003

32 Yildirim M, Spiekermann H, Biesterfeld S and Edelhoff D: Maxillary sinus augmentation using xenogenic bone substitute material bio-oss ${ }^{\circledR}$ in combination with venous blood: A histologic and histomorphometric study in humans. Clin Oral Implants Res 11(3): 217-229, 2000. PMID: 11168213.
33 Cordaro L, Bosshardt DD, Palattella P, Rao W, Serino G and Chiapasco M: Maxillary sinus grafting with bio-oss ${ }^{\circledR}$ or straumann ${ }^{\circledR}$ bone ceramic: Histomorphometric results from a randomized controlled multicenter clinical trial. Clin Oral Implants Res 19(8): 796-803, 2008. PMID: 18705811. DOI: 10.1111/j.1600-0501.2008.01565.x

34 Lee YM, Shin SY, Kim JY, Kye SB, Ku Y and Rhyu IC: Bone reaction to bovine hydroxyapatite for maxillary sinus floor augmentation: Histologic results in humans. Int J Periodontics Restorative Dent 26(5): 471-481, 2006. PMID: 17073357.

35 Binderman I, Yaffe A, Samuni Y, Bahar H, Choukroun J and Russe P: Tissue engineering of bone: Critical evaluation of scaffold selection. In: Bone regeneration. InTech pp. 83-94, 2012. DOI: $10.5772 / 33004$

36 Mangano C, Scarano A, Perrotti V, Iezzi G and Piattelli A: Maxillary sinus augmentation with a porous synthetic hydroxyapatite and bovine-derived hydroxyapatite: A comparative clinical and histologic study. Int J Oral Maxillofac Implants 22(6): 980-986, 2007. PMID: 18271380.

37 Piattelli M, Favero GA, Scarano A, Orsini G and Piattelli A: Bone reactions to anorganic bovine bone (Bio-Oss) used in sinus augmentation procedures: A histologic long-term report of 20 cases in humans. Int J Oral Maxillofac Implants 14(6): 835-840, 1999. PMID: 10612920.

38 Scarano A, Degidi M, Iezzi G, Pecora G, Piattelli M, Orsini G, Caputi S, Perrotti V, Mangano C and Piattelli A: Maxillary sinus augmentation with different biomaterials: A comparative histologic and histomorphometric study in man. Implant Dent 15(2): 197-207, 2006. PMID: 16766904. DOI: 10.1097/01.id.0000220120.54308.f3

Received August 8, 2019

Revised September 15, 2019

Accepted September 16, 2019 